\title{
Effect of surface preparation treatments on copper enrichment on 2024 aluminium alloy surface
}

Camille TRINIDAD ${ }^{\mathrm{a}, \mathrm{b}}$, Jolanta ŚWIATOWSKA ${ }^{\mathrm{a}^{*}}$, Sandrine ZANNA ${ }^{\mathrm{a}}$, Antoine SEYEUX ${ }^{\mathrm{a}}$, Dimitri Mercier $^{a}$, Rémi VIROULAUD ${ }^{b}$, Philippe MARCUS ${ }^{{ }^{*}}$

${ }^{a}$ Chimie ParisTech - CNRS, PSL University, Institut de Recherche de Chimie Paris, Physical Chemistry of Surfaces Group, 11 rue Pierre et Marie Curie, 75005 Paris, France

${ }^{\mathrm{b}}$ Technological Research Institute Materials, Metallurgy and Processes, 12 rue de l'artisanat, 67120, Duppigheim, France

\section{Abstract}

X-ray photoelectron spectroscopy (XPS) and time-of-flight secondary ion mass spectrometry (ToFSIMS) were used to analyse the surface modifications of AA-2024-T3 induced by model pretreatment baths such as $\mathrm{H}_{2} \mathrm{SO}_{4}, \mathrm{HNO}_{3}$, and in a mixture of both acids. These acids are commonly used for pickling treatment, applied before conversion coating deposition.

ToF-SIMS and XPS measurements showed a significant copper enrichment in metallic and oxidised states, localised at the oxide/metal interface. The sulphuric acid treatment led to the highest $\mathrm{Cu}$ enrichment. A lower dissolution rate of AA-2024 was observed by inductively coupled plasma optical emission spectroscopy (ICP-OES). It was concluded that the surface enrichment in $\mathrm{Cu}$ is mainly associated with dealloying of intermetallic particles by selective dissolution of the less noble elements.

Keywords: aluminium alloy 2024-T3; surface pre-treatment; copper enrichment; XPS; ToFSIMS

\footnotetext{
"Corresponding authors: Jolanta Światowska, email: jolanta.swiatowska@chimieparistech.psl.eu, and Philippe Marcus, email: philippe.marcus@chimieparistech.psl.eu
} 


\section{Introduction}

High strength aluminium alloys are widespread in aircraft industry for their low weight and good mechanical performance due to the addition of alloying elements in the aluminium matrix such as $\mathrm{Cu}, \mathrm{Fe}$ and $\mathrm{Mg}$. The AA-2024-T3 is one of the most commonly used alloys for the fuselage [1]. The intermetallic particles formed by precipitation of alloying element provide active sites for the localised corrosion due to their either cathodic $\left(\theta-\mathrm{Al}_{2} \mathrm{Cu}\right)$ or anodic ( $\mathrm{S}-\mathrm{Al}_{2} \mathrm{CuMg}$ ) nature relative to the surrounding matrix [2]. Thus, a coating is needed for good corrosion protection of these alloys.

For the last few decades, corrosion protection has been provided by chromate conversion coating or anodising. Hexavalent chromate conversion coatings (CCC) were the most applied anticorrosive treatments for aluminium alloys [3]. Due to the toxicity of chromium (VI), alternative corrosion inhibitors have been developed such as trivalent chromium, rare-earth, permanganate, molybdate or vanadate -based conversion coatings [3-11]. The conditions to obtain an optimal conversion coating are not clearly understood due to lack of knowledge on coating formation mechanisms. The conversion coating formation is strongly influenced by the alloy surface preparation, which appears as a key step for the conversion process $[4,7,12,13]$.

Surface preparation is known to influence the properties of the coatings $[4,12-17]$. The pretreatment should allow to remove lubricant to clean the surface, standardize and control the chemical composition of the alloy surface to improve conversion coating performances. Prior to the conversion, two types of pre-treatments by immersion are usually used. First, a degreasing allows to clean the surface by removing some greases and fabrication oils. 
Second, pickling/deoxidizing/desmutting, which denote the same process, allow to remove the oxide layer and the intermetallic particles and to form a new, fresh oxide.

An acid deoxidizer often contains nitric acid to dissolve the oxide film. However nitric acid is not sufficient to remove all intermetallic particles, and it is often used with other acids such as sulphuric acid, phosphoric acid, hydrofluoric acid or bromic acid. During deoxidizing, the attack can lead also to the nanotexturing of the matrix, generally denoted as a scalloped surface [18]. The cathodic particles undergo trenching of the surrounding matrix and the anodic intermetallic particles are subject to the dealloying mechanism. Due to the dealloying the intermetallic particle more cathodic potential can be observed and trenching occurs in the matrix $[2,19]$. Many authors provided evidence of a copper enrichment at the surface during acid deoxidizing [4,12,20-23]. Moffit et al. [21] studied the evolution of alloying element content during various surface preparations and showed that the highest quantity of $\mathrm{Cu}$ enrichment occurs in the case of $\mathrm{HNO}_{3}-\mathrm{HF}$ deoxidizing process without degreasing. Viroulaud et al. [4] observed a $\mathrm{Cu}$ enrichment beneath the oxide after degreasing and deoxidizing attributed to a selective dissolution of Al and Mg occurring principally in IMPs, with possible release of copper. Liu et al. [23] found a copper enrichment increased by a factor of 15 between $30 \mathrm{~s}$ and $300 \mathrm{~s}$ immersion of 2024-T3 in nitric acid. The formation of around $1 \mathrm{~nm}$-thick copper layer at the oxide/Al-Cu metal interface after $300 \mathrm{~s}$ of immersion in nitric acid was also evidenced.

The surface preparation and the conversion treatment should perfectly match to grow a resistant coating. In fact, all deoxidizers are not adapted to all conversion processes [12]. Authors have shown alteration of the coating's homogeneity, which can be explained by aggressive conditions of deoxidizers and too long immersion time $[4,13]$. There are only few 
studies on the influence of copper enrichment on the coating deposition and the corrosion properties. Verdalet-Guardiola et al. [15] demonstrated that the copper enrichment led to a less protective coating whereas Viroulaud et al. [4] showed that a strong $\mathrm{Cu}$ enrichment on AA-2024 alloy was not detrimental for coating quality.

The aim of this work is to determine the role of nitric and sulphuric acids, which are mainly present in deoxidizing baths and particularly in the sulfo-nitro-ferric baths, on the chemical composition of the surface of a 2024-T3 aluminium alloy. The surface morphology, chemistry and the constituent dissolution of a 2024-T3 alloy after deoxidizing were investigated in details. Three deoxidizer baths were tested: nitric and sulphuric acids alone and the mixture of both acids.

\section{Experimental}

\subsection{Materials}

High strength aluminium alloy AA-2024-T3 was chosen to investigate acid bath pretreatments. The specification of 2024 alloy is: $\mathrm{Cu}(3.8-4.9 \mathrm{wt} \%), \mathrm{Mg}(1.2-1.8 \mathrm{wt} \%), \mathrm{Mn}(0.3-$ 0.9 wt\%), Fe (0.5 wt\%), Si (0.5 wt\%), Zn (0.25 wt\%), Ti (0.15 wt\%), Cr (0.1 wt\%), and Al (balance). The T3 thermal treatment is a solution treatment (at $495 \pm 5{ }^{\circ} \mathrm{C}$ ) followed by a cold strain-hardening and finished by aging at ambient temperature for minimum 4 days. 1 $\mathrm{mm}$-thick rolled sheet panels obtained from the IRT-M2P (France) were used as substrates. Substrates were cut in $1 \times 1 \mathrm{~cm}^{2}$ samples.

A pure aluminium $99.9999 \%$ purchased from Goodfellow was used to perform comparative studies with results obtained on 2024-T3. A $3 \mathrm{~mm}$ thick panel was used. Samples were cut in $1 \times 1 \mathrm{~cm}^{2}$ square sheets. 
Substrates were grinded with SiC grinding paper from 1200 to 2400 grades. Then, they were polished with alumina paste ranging from 2-3 $\mu \mathrm{m}$ to $0.5 \mu \mathrm{m}$. This mirror-finish surface before and after pre-treatments was necessary for XPS, ToF-SIMS and SEM analyses. The other side of the sample was grinded with SiC paper 1200 to have similar surface finishing and reactivity in the pre-treatment baths used for analysis by ICP-OES. Solvent cleaning in ultrasonic bath was done during $2 \mathrm{~min}$ in propan-2-ol and then $2 \mathrm{~min}$ in ethanol.

Three pre-treatment baths were used: $100 \mathrm{~g} / \mathrm{L} \mathrm{HNO}_{3}, 150 \mathrm{~g} / \mathrm{L} \mathrm{H}_{2} \mathrm{SO}_{4}$ and a mixture of both acids in same concentration ranges. These concentrations have been chosen to be comparable with the Socosurf bath, which is a $\mathrm{HNO}_{3}-\mathrm{H}_{2} \mathrm{SO}_{4}-\mathrm{Fe}$ (III) commercial bath. The baths were diluted with ultra-pure Millipore ${ }^{\circledR}$ water (resistivity of $18.1 \mathrm{M} \Omega . \mathrm{cm}$ ). Samples were immersed in $75 \mathrm{~mL}$ baths during $10 \mathrm{~min}$ at $50{ }^{\circ} \mathrm{C}$ and rinsed during $2 \mathrm{~min}$ in ultra-pure water. Then, they were dried under filtered compressed air. They were quickly transferred to the analysis (in less than 1 hour).

\subsection{XPS, ToF-SIMS, SEM and ICP-OES characterizations}

Surface chemical analyses were performed with an XPS Thermo Electron Escalab 250 spectrometer. The vacuum was below $2 \times 10^{-9}$ mbar during analysis. A disk of around $500 \mu \mathrm{m}$ of diameter is analysed with a take-off angle of $90^{\circ}$. X-Rays were provided from a monochromatic Al Ka source $(\mathrm{hv}=1486.6 \mathrm{eV})$. Acquisitions of survey spectra with a pass energy of $100 \mathrm{eV}$ and high-resolution core level spectra ( $\mathrm{Al} 2 \mathrm{p}, \mathrm{Al} 2 \mathrm{~s}, \mathrm{Cu} 2 \mathrm{p}, \mathrm{Mg}$ 1s) and Auger spectra (Cu LMN) with a pass energy of $20 \mathrm{eV}$ were performed. Calibration of the spectrometer was carried out with $\mathrm{Au} 4 \mathrm{f} 7 / 2$ at $84.1 \mathrm{eV}$. The AvantageTM software (Thermo ElectronCorp.) was used to fit the spectra with a Shirley type background and 
Lorentzian/Gaussian 30/70 peak shape for oxides. The CasaXPS processing software was also used for the fitting of Cu LMN spectra.

A ToF-SIMS V spectrometer (Ion ToF $\mathrm{GmbH}$ ) operating at $10^{-9} \mathrm{mbar}$ vacuum was used to perform in-depth profile analysis. The depth profiles were obtained using a dual beam mode: a pulsed $25 \mathrm{keV} \mathrm{Bi}^{+}$primary ion source (LMIG) as the analysis beam delivering a $1.2 \mathrm{pA}$ current and rastering an area of $100 \times 100 \mathrm{\mu m}^{2}$, and a $2 \mathrm{keV} \mathrm{Cs}^{+}$ion beam as the sputtering beam delivering a $100 \mathrm{nA}$ current and rastering an area of $700 \times 700 \mu \mathrm{m}^{2}$. Profile acquisitions were performed in negative ion mode because providing higher sensitivity for oxides. Data acquisition and post-processing analysis were performed using the lon-Spec software. The ion depth profiles were normalised with reference to $\mathrm{Al}_{2}{ }^{-}$intensity plateau, corresponding to the alloy substrate. The intensities of all ions were divided by the value of $\mathrm{Al}_{2}^{-}$ion intensity (in the plateau region).

SEM images were obtained with a ZEISS Ultra-55 field emission scanning electron microscope (FE-SEM) in standard conditions. A voltage of $10 \mathrm{kV}$ and a pressure inside the chamber less than $2.10^{-5}$ mbar were used. EDX Analysis were performed on a LEICA S440 emission scanning electron microscope (FEG-SEM) couple with an energy-dispersive X-ray spectroscopy (EDX) detector at the LISE (UMR8235-UPMC/CNRS).

An ICP-OES iCAP 6300 (Thermo Fisher Scientific) was used to measure the concentration of dissolved species in the baths at the end of pre-treatments. This allows us to estimate the surface dissolution rates in the bath. Standards of $\mathrm{Al}, \mathrm{Cu}, \mathrm{Mg}$ from $0.01 \mathrm{ppm}$ to $50 \mathrm{ppm}$ were used to calibrate the instrument. The concentration of dissolved species was normalised to the average of sample area $\left(1.6 \mathrm{~cm}^{2}\right.$ for $2024-\mathrm{T} 3$ and $2.5 \mathrm{~cm}^{2}$ for pure aluminium). Front 
sides of the samples were mirror polished (as described above) and the back sides were grinded with SiC paper (1200).

\section{Results}

\subsection{Surface morphology}

Scanning electron microscopy (SEM) with energy-dispersive X-ray (EDX) spectroscopy have been performed on a polished AA-2024-T3 to investigate the topography and the type of intermetallic particles. SEM images (Fig. 1, A)) of AA-2024-T3 show the presence of many particles with different sizes and shapes. Some holes (dark areas) correspond to particles removed during the polishing. According to EDX and SEM measurements, round-shaped particles with an approximate size of $1 \mu \mathrm{m}$ are associated to $\Theta-\mathrm{Al}_{2} \mathrm{Cu}$ and $\mathrm{S}-\mathrm{Al}_{2} \mathrm{CuMg}$ phases. Bigger particles with irregular shapes correspond to Al-Cu-Fe-Mn-Si phases with an average stoichiometry of $\mathrm{Al}_{21} \mathrm{Cu}_{6} \mathrm{Fe}_{2} \mathrm{MnSi}_{0.3}$. X-ray diffraction (XRD) measurements (not presented here) confirmed the presence of $\Theta-\mathrm{Al}_{2} \mathrm{Cu}$ and $\mathrm{S}-\mathrm{Al}_{2} \mathrm{CuMg}$ phases. $\mathrm{Al}_{7} \mathrm{Cu}_{2} \mathrm{Fe}$ phase was also identified. The Al-Cu-Fe-Mn-Si phase could originate from $\mathrm{Al}_{7 \mathrm{Cu}_{2} \mathrm{Fe}}$ with manganese substituting iron. Hughes et al. [24] have identified 6 phases from different samples of AA2024-T3, including S-phase, $\Theta-$ phase and Al-Cu-Fe-Mn-Si. They evidenced that the various compositions and distributions of more than 3 types of intermetallics can be influenced by aging conditions. Indeed, in our study, the alloy presents many particles with a size below the micrometre but the EDX measurements were performed on particles not smaller than one micrometer. Verdalet-Guardiola [25] also identified disparities of intermetallic particles recovery rates and distribution on three types of 2024-T3 alloys from different suppliers. 
Fig. 1, B) presents the EDX image of AA-2024-T3 polished sample. According to the previous analysis, it is possible to observe the $\mathrm{Al}-\mathrm{Cu}, \mathrm{Al}-\mathrm{Cu}-\mathrm{Mg}$ and $\mathrm{Al}-\mathrm{Cu}-\mathrm{Fe}-\mathrm{Mn}$-Si particles. As shown by the elemental mapping, the particles are randomly distributed. It is noted that copper is the alloy element observed on all particles.
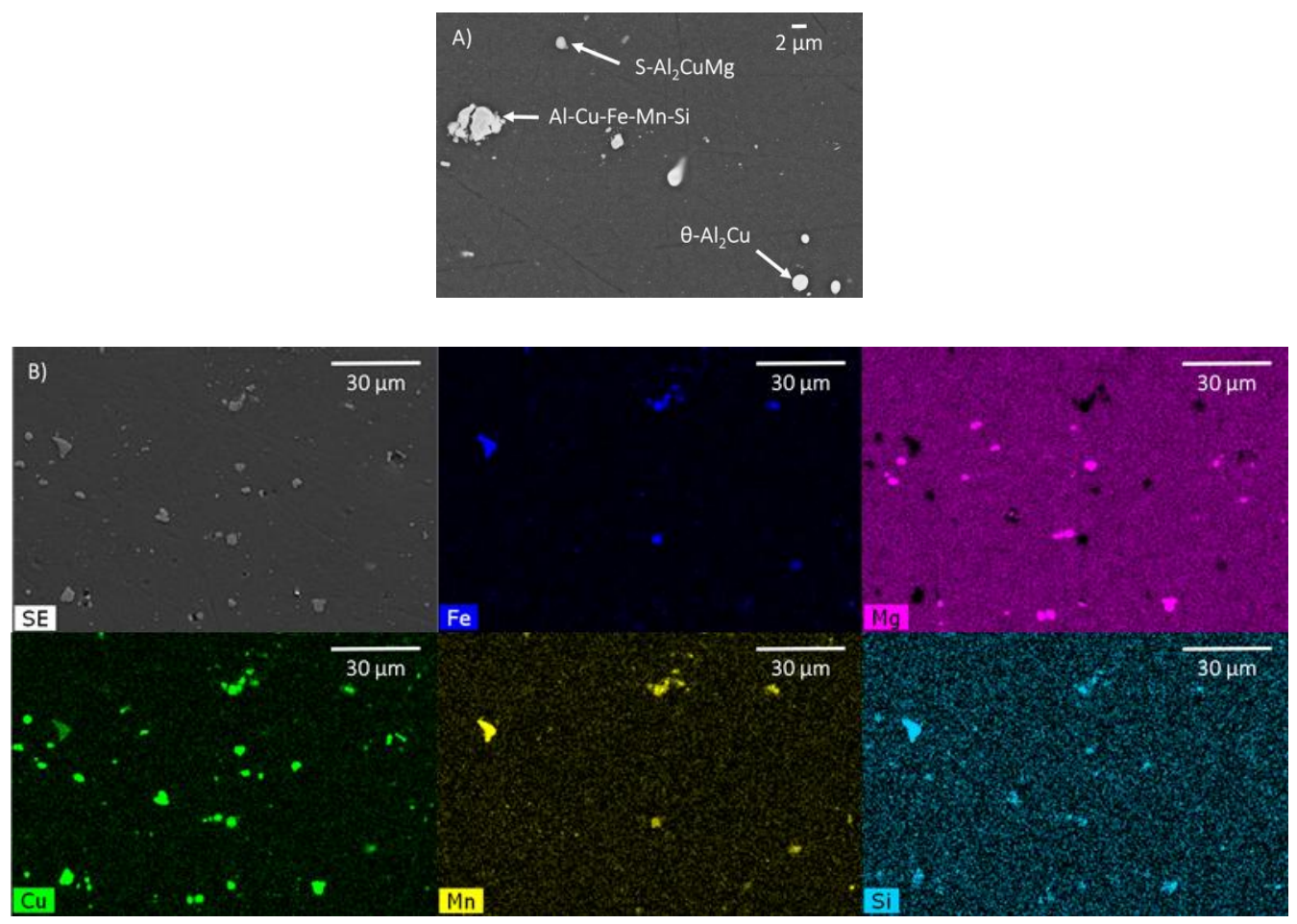

Fig. 1. SEM images of polished AA-2024-T3 alloy observed with secondary electrons (A) and B) EDX images) of a polished 2024-T3 alloy.

Fig. 2 presents SEM secondary electrons images of AA-2024-T3 samples surface after pretreatments $\mathrm{A}-\mathrm{C}$ ) nitric acid, $\mathrm{D}-\mathrm{H}$ ) sulphuric acid and $\mathrm{I}-\mathrm{L}$ ) mixture of nitric and sulphuric acids. At lower magnification (Fig. 2, A), D) and I)), SEM images show modifications of the intermetallic particles and the matrix with presence of several holes resulting from the removal of intermetallic particles induced by different pre-treatments. The remnant intermetallic particles (light colour) present various shapes, sizes and textures. As described above (Fig. 1), the round-shaped particles of $1 \mu \mathrm{m}$ in size correspond to $\Theta-\mathrm{Al}_{2} \mathrm{Cu}$ and S- 
$\mathrm{Al}_{2} \mathrm{CuMg}$ phases, whereas the irregular in shape and bigger particles to $\mathrm{Al}-\mathrm{Cu}-\mathrm{Fe}-\mathrm{Mn}-\mathrm{Si}$. The Al-Cu-Fe-Mn-Si particles are easily recognized, and detailed analyses on these particles were performed.

Most of intermetallic particles seem not to be attacked during pre-treatment in nitric acid (Fig. 2, A) and B)). Only smaller particles, associated to $\Theta-\mathrm{Al}_{2} \mathrm{Cu}$ and $\mathrm{S}-\mathrm{Al}_{2} \mathrm{CuMg}$, seem to be attacked. Some of them have been removed (dark holes), and some of them have been partially attacked and present a spongy texture (Fig. 2, C)). Particles with this spongy texture are composed of a continuous solid phase remnant network and many nanosized pores [26]. This phenomenon already observed for the 2024-T3 alloy after 15 min treatment in $2.8 \mathrm{M}$ $\mathrm{HNO}_{3}$ bath [27] is known as dealloying. This was also evidenced for $\mathrm{Al}(\mathrm{Cu}, \mathrm{Mg})$ phase in the case of AA-2024-T3 after oxidising acid pickling in Turgo Smut Go NC by Alba-Galvin et al. [17]. This type of morphology results from the preferential dissolution of aluminium, and magnesium in the case of S-phase. Two phenomena can be distinguished: either copper enrichment of the particle which becomes more cathodic, or small copper particles detachment from intermetallic copper, which create an electrochemical cell surrounding the S-phase. It leads to the dissolution of surrounding matrix in both cases, called trenching $[19,28,29]$.

After a pre-treatment in sulphuric acid, (Fig. 2, E-G)), more dealloyed particles are observed than after the pre-treatment in nitric acid (Fig. 2, D)). Concerning dealloyed particles, some particles are completely dealloyed and the matrix is dissolved around the particles, some particles are only attacked in their centre.

In the mixture of both acids (nitric and sulphuric), the alloy surface appears more attacked (Fig. 2, I)) showing holes with entirely or partially removed particles. All remnant particles 
are dealloyed and some of them present a kind of light mist (Fig. 2, K)). In attacked large and irregular particles, the continuous solid phase remnant network and pores (Fig. 2, L)) are more significant than after pre-treatment in sulphuric acid ((Fig. 2, H)). These particles are likely Al-Cu-Fe-Mn-Si particles according to their sizes and irregular shapes.

EDX measurements were performed on the sample pre-treated in $150 \mathrm{~g} / \mathrm{L} \mathrm{H}_{2} \mathrm{SO}_{4}$ and $100 \mathrm{~g} / \mathrm{L}$ $\mathrm{HNO}_{3}$. Results are presented in Fig. 3. According to the shape, size and constituents, these dealloyed particles seem to be Al-Cu-Fe-Mn-Si-type particles. The analysis performed on dealloyed areas showed copper rich-areas with copper/aluminium ratio of 0.9 and 0.6 for areas 1 and 2, respectively. A second analysis performed on a particle partially attacked showed that the dealloyed area (area 3) contains more copper than the intact area (area 4). These EDX analyses confirm the copper enrichment of dealloyed particles due to preferential dissolution.

It can be concluded that different samples morphologies were identified depending on acids treatments. The sample pretreated in mixture of acids seems the most modified with many removed and/or dealloyed particles. Moreover, the size of continuous solid phase remnant networks of the dealloyed particles was shown to be dependent on the pre-treatment conditions. Hashimoto et al. [26] studied the dealloying phenomenon of $S$ and $\theta$ phases in $1.5 \mathrm{M} \mathrm{NaCl}$ media, and they demonstrated the gradual evolution of pore size and a continuous formation of solid phase remnant network during dealloying. From nanosized pores and a relatively fine remnant at the beginning, it evolves to relatively large pores and a coarser-remnant network. This could mean the beginning state of dealloying for the sample pretreated in sulphuric acid whereas the more severe attack can be observed for the sample pretreated in mixture of acids. Moreover, authors highlighted the presence of copper 
nanoparticle at the intersection of remnant branches of dealloyed particles and these particles were covered of $2 \mathrm{~nm}$ thick copper film. Qi et al. [30] also showed the crystallization of $\mathrm{Cu}$ (111), (2000), (220) and (311) on the surface of a dealloyed Al-Cu alloy after immersion in $\mathrm{HCl}$ media at $90^{\circ} \mathrm{C}$ during a few hours.
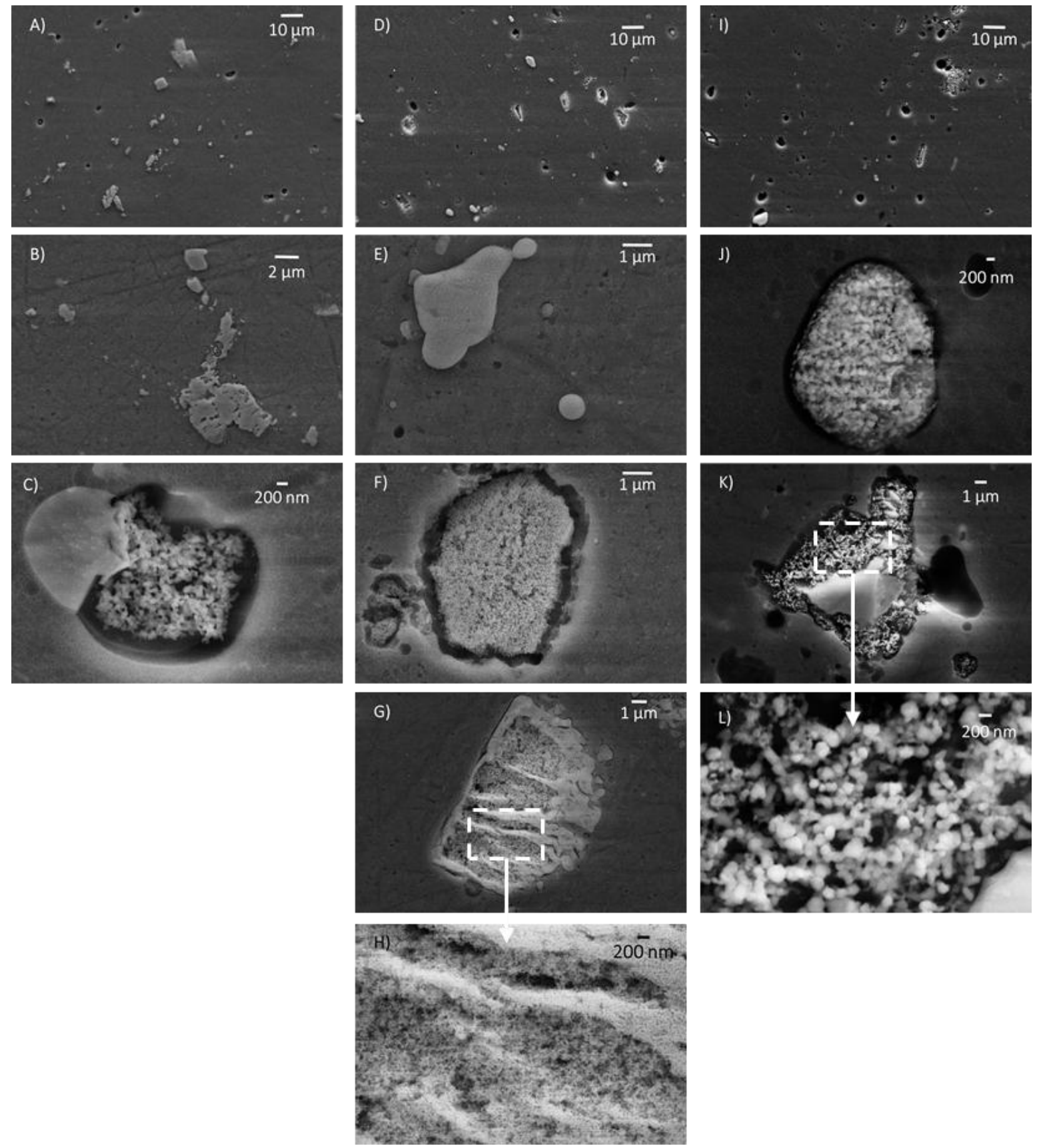

Fig. 2. SEM images of AA-2024-T3 alloy after pre-treatments in A-C) $100 \mathrm{~g} / \mathrm{L}$ nitric acid, $D-H$ ) $150 \mathrm{~g} / \mathrm{L}$ sulphuric acid and I-L) mixture of $150 \mathrm{~g} / \mathrm{L}$ sulphuric acid and $100 \mathrm{~g} / \mathrm{L}$ nitric acid observed by SEM (secondary electrons, $10 \mathrm{kV}$ ). 

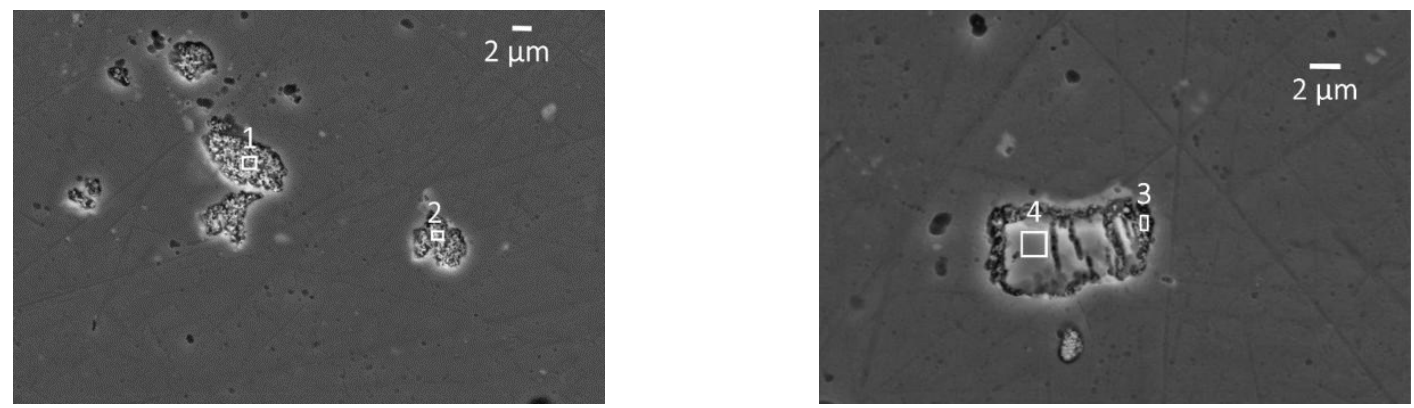

\begin{tabular}{|c|c|c|c|c|c|}
\hline At\% & Area 1 & Area 2 & Area 3 & Area 4 \\
\cline { 2 - 6 } & Aluminium & 47 & 55 & 69 & 78 \\
\cline { 2 - 6 } & Copper & 44 & 35 & 29 & 9 \\
\cline { 2 - 6 } & Iron & 6 & 7 & 1 & 10 \\
\cline { 2 - 6 } & Manganese & 3 & 4 & 1 & 3 \\
\hline
\end{tabular}

Fig. 3. EDX measurements (and SEM backscattered electrons at a voltage of $15 \mathrm{kV}$ ) of the AA2024-T3 sample pre-treated in a mixture of $150 \mathrm{~g} / \mathrm{L}$ sulphuric acid and $100 \mathrm{~g} / \mathrm{L}$ nitric acid.

\subsection{In-depth chemical characterisation by ToF-SIMS}

Chemical surface and in-depth characterisations were performed by ToF-SIMS ion depth profiling. The ToF-SIMS ion depth profiles for a polished AA-2024-T3 sample are presented in Fig. 4. The intensity of ion signals is reported in logarithmic scale. Although ToF-SIMS is not directly quantitative, signal intensity changes with sputtering time reflect in-depth concentration variations. Observing the intensity changes of different ions with sputtering time, three different regions can be identified in the in- depth profile: oxide layer, oxide/metal interfacial zone and the metallic substrate.

The first one, corresponding to the first $35 \mathrm{~s}$ of sputtering, is characterized by the maximum intensity of $\mathrm{AlO}_{2}^{-}(\mathrm{m}=58.98 \mathrm{amu})$ signal whereas the $\mathrm{Al}_{2}^{-}(\mathrm{m}=53.96 \mathrm{amu})$ and $\mathrm{Cu}^{-}(\mathrm{m}=62.93$ amu) signals, characteristic of the metal, remains low. This region is associated to the oxide layer, which is mainly composed of oxidized aluminium. The second region starts with the decrease of the $\mathrm{AlO}_{2}^{-}$signal intensity, which corresponds to the increase of $\mathrm{Al}_{2}{ }^{-}, \mathrm{CuO}^{-}$ 
$(\mathrm{m}=78.92 \mathrm{u})$ and $\mathrm{Cu}^{-}$signals. After $35 \mathrm{~s}$, the maximum intensity of $\mathrm{CuO}^{-}$and $\mathrm{Cu}^{-}$(markers of copper hydroxide/oxide and metallic copper, respectively [31]) are reached and the $\mathrm{Al}_{2}^{-}$is still increasing. This suggests an interfacial region rich in copper, due to the presence of $\mathrm{Cu}$ rich intermetallic particles located at the interface between metal and oxide. This region, that extends from $35 \mathrm{~s}$ to $85 \mathrm{~s}$, corresponds to both the oxide and metallic substrate as the roughness of the sample is significant, as already discussed previously $[4,32,33]$. In this region, the $\mathrm{CuO}^{-}$signal shows a maximum of intensity at $45 \mathrm{~s}$, whereas the maximum intensity of $\mathrm{Cu}^{-}$signal is observed $5 \mathrm{~s}$ later (at $50 \mathrm{~s}$ ). Despite the complex effect of sample roughness, which can influence the shape of ion profiles in the interfacial region, the slow decay of $\mathrm{CuO}^{-}$signal, that follows the trend of $\mathrm{Cu}^{-}$signal, indicates the presence of copper oxide at the periphery of Cu-rich intermetallic particles. This was previously evidenced by Cornette et al. [31]. The presence of copper oxide on intermetallic particles is not expected from thermodynamics, which predicts a preferential growth of an aluminium oxide as long as the intermetallic particle contains sufficient metallic aluminium. The presence of copper oxide would mean that preferential oxidation of aluminium on the intermetallic surface leads to complete depletion of aluminium, so that then copper oxidation becomes possible at the intermetallic particle surface. The $\mathrm{MgO}^{-}$signal also reaches its maximum intensity at around $50 \mathrm{~s}$, indicating that magnesium oxide is located close to the interface. Then, the last, third region after $85 \mathrm{~s}$, characterised by the of $\mathrm{Al}_{2}{ }^{-}$intensity plateau corresponds to the metallic substrate. Summarizing, the alloy is covered by an aluminium oxide and is enriched in copper at the metal/oxide interface due to the oxidation process of intermetallic particles. Similar profiles have been observed previously $[4,31,32,34]$. 


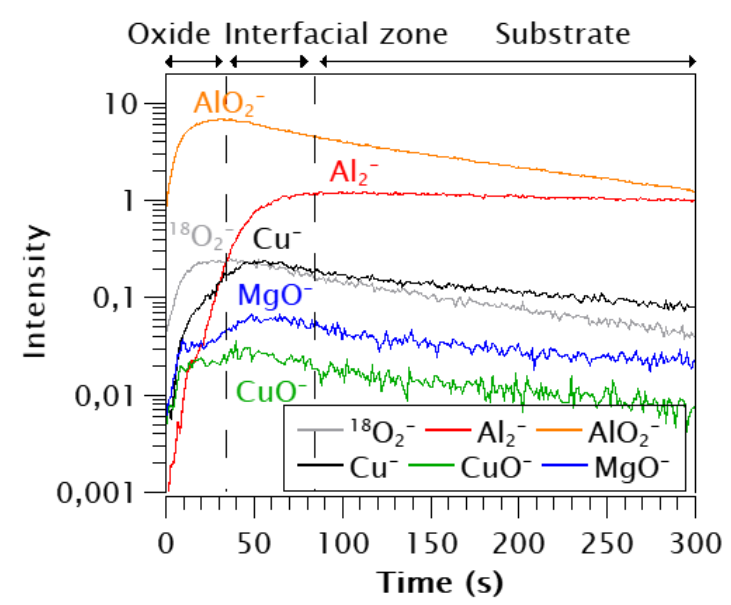

Fig. 4. ToF-SIMS ion depth profiles recorded for a mirror polished AA-2024-T3 alloy.

A comparison of the in-depth profiles for polished sample and pretreated samples in sulphuric acid (Fig. 5, A)) and in nitric acid and a mixture of acids (Fig. 5, B)) is shown in Fig. 5. The time to reach the interfacial zone is longer for the samples immersed in sulphuric acid (50 s) and in the mixture of acids (45 s) than for the polished sample ( $35 \mathrm{~s}$ as presented in Fig. 4). The sputtering time to reach the substrate is longer for all pretreated samples, especially after the treatment in the mixture of acids (150 s). Assuming the same sputtering yield for all samples (as the composition of the oxide scales is similar), the data indicate that slightly thicker oxide layers are present on pretreated samples. However, the slower stabilization of $\mathrm{Al}_{2}{ }^{-}$signal to its maximum intensity (plateau) can also be also induced by a higher roughness of pretreated samples.

Concerning copper species, the $\mathrm{Cu}^{-}$signal reaches its maximum intensity in the interfacial zone as for the polished sample. The maximum signal intensities are 10 times higher after immersion in acid baths. This is characteristic of a copper enrichment induced by the pretreatments. Similarly to our findings, the copper enrichment at the oxide/metal interface of AA-2024-T3 was already observed by XPS depth profiles by Vander et al. [22] after a 
Sanchem pre-treatment (phosphate cleaner with no silicate bath then sodium bromate in nitric acid bath). Using TEM, Liu et al. [23] evidenced the presence of $1 \mathrm{~nm}$ thick copper enrichment underlying the alloy region for $\mathrm{Al}-\mathrm{Cu}$ magnetron sputtered alloy immersed in nitric acid. For the sample immersed in sulphuric acid (Fig. 5, A), a high $\mathrm{CuO}^{-}$signal intensity spreads through the whole oxide region. Moreover, the $\mathrm{Cu}^{-}$signal increases quickly from the firsts $5 \mathrm{~s}$ of sputtering to reach its maximum intensity close to the metal/oxide interface. The intense $\mathrm{CuO}^{-}$and $\mathrm{Cu}^{-}$signals through the oxide layer can be explained by the dissolution of Cu-rich intermetallic particles then the redeposition of metallic copper over the surface, which subsequently undergoes the oxidation. The copper redeposition was also evidenced by Buchheit et al. [29] and Viroulaud [35]. Zhou et al. [36] and Liu et al. [37] demonstrated the incorporation copper into the oxide film as oxidized species and nanoparticles which subsequently oxidized. The maximum intensity of $\mathrm{Cu}^{-}$in the interfacial zone indicates a copper enrichment at the metal/oxide interface.

In order to compare $\mathrm{Cu}$ enrichment in different samples, the $\frac{\mathrm{Cu}^{-}}{\mathrm{Al}_{2}{ }^{-}}$signal ratios have been plotted (Fig. 6). The differences are visible in the first 75 seconds of sputtering showing the copper enrichment in the oxide and interfacial zones. The polished sample shows the lowest ratio, the sulphuric acid treatment leads to the highest $\frac{\mathrm{Cu}^{-}}{\mathrm{Al}_{2}{ }^{-}}$ratio. 

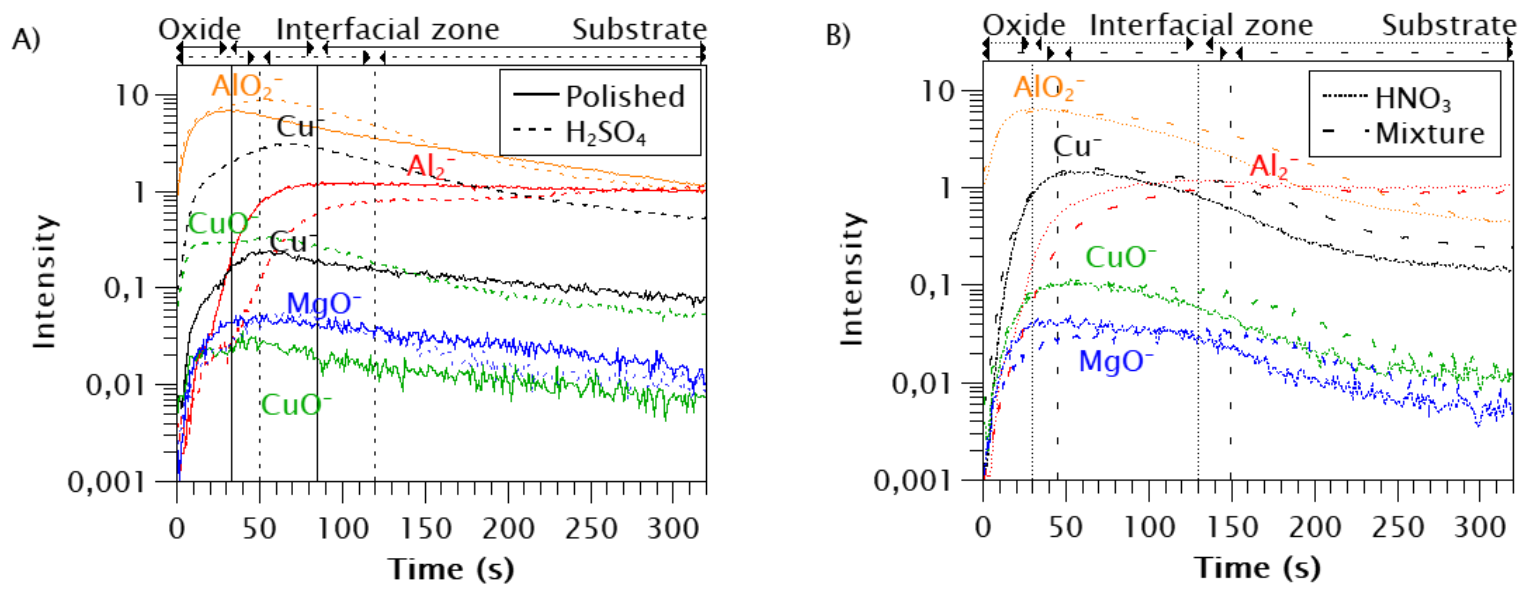

Fig. 5. Comparison of ToF-SIMS ion depth profiles for A) polished sample and sample pretreated in sulphuric acid, B) samples pretreated in nitric acid and a mixture of nitric and sulphuric acids.

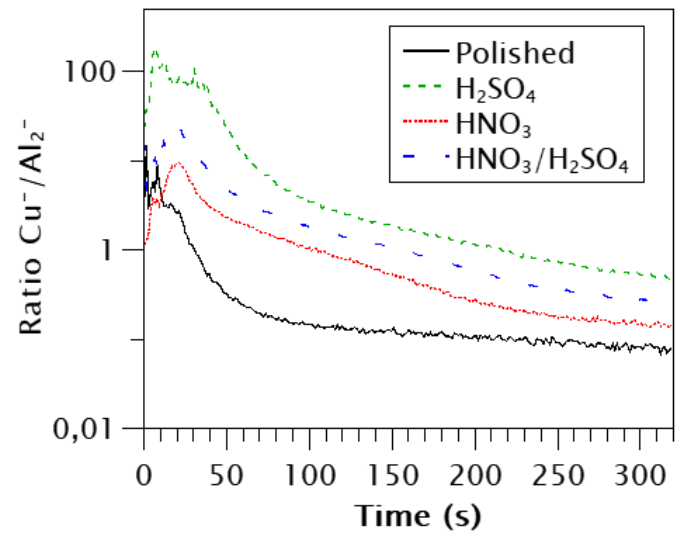

Fig. 6. Comparison of $\frac{\mathrm{Cu}^{-}}{\mathrm{Al}_{2}^{-}}$ratios for polished and pretreated samples.

\subsection{Chemical analysis of surfaces by XPS}

The surface chemical analysis of all samples before and after pre-treatment was performed by XPS. High-resolution $\mathrm{Al} 2 \mathrm{~s}, \mathrm{Cu} 2 \mathrm{p}$ and $\mathrm{Cu}$ LMN spectra have been used to obtain the surface composition and to estimate the copper enrichment induced by pre-treatments. The results for the polished sample and $\mathrm{HNO}_{3}$ pre-treated sample are presented in Fig. 7 . The carbon, not shown here, is attributed to surface contamination. The position of the $\mathrm{C}-\mathrm{C}$ bond 
is $286.1 \pm 0.1 \mathrm{eV}$ and $286.2 \pm 0.1 \mathrm{eV}$ for polished sample and pre-treated in $\mathrm{HNO}_{3}$, respectively. The nonconductive oxide layer above metallic aluminium is responsible of the $\mathrm{C}-\mathrm{C}$ shift to higher binding energy than the $285 \mathrm{eV}$ position expected for $\mathrm{C}-\mathrm{C}$ bonds. The overlap of Al $2 p$ and $\mathrm{Cu} 3 p$ peaks prevents using Al $2 p$ core level for quantitative analysis. Al $2 \mathrm{~s}$ spectra are fitted with peaks corresponding to the metallic aluminium at $118 \pm 0.1 \mathrm{eV}$ and Al(III) oxide/hydroxide at $120.6 \pm 0.2 \mathrm{eV}$ (Fig. 7, A) and B)) [38]. Cu 3s appears in the binding energy range of $\mathrm{Al} 2 \mathrm{~s}$ core level spectrum at $123.1 \pm 0.2 \mathrm{eV}$. $\mathrm{Al}(\mathrm{III})$ and $\mathrm{Al}(0)$ peaks (Fig. 7, B)), associated to aluminium oxide and metal, respectively, show a similar intensity ratio indicating no significant modifications in the oxide layer thickness. However, an increase of $\mathrm{Cu} 3 \mathrm{~s}$ signal observed after pre-treatment in nitric acid indicates a copper enrichment.

The analysis of $\mathrm{Cu} 2 \mathrm{p}$ and $\mathrm{Cu}$ LMN spectra presented hereafter allows us to determine the chemical state of copper. For the polished sample, three components are present in the $\mathrm{Cu}$ $2 p_{3 / 2}$ core level region (Fig. 7, C)): at $932.6 \pm 0.1 \mathrm{eV}, 933.6 \pm 0.2 \mathrm{eV}$, and $934.8 \pm 0.1 \mathrm{eV}$. The first peak at $932.6 \pm 0.1$ is attributed to $\mathrm{Cu}(\mathrm{I})$ and $\mathrm{Cu}(0)[39,40]$. The presence of copper metal and oxide has been confirmed by the analysis of Auger $\mathrm{Cu}$ LMN line (Fig. 7, E)) discussed below. The second peak at $933.6 \pm 0.2 \mathrm{eV}$ can be associated to metallic copper in the intermetallic particles. For pure metallic copper, the $\mathrm{Cu} 2 \mathrm{p}_{3 / 2}$ peak is expected at $932.6 \pm$ $0.1 \mathrm{eV}[39,40]$ but according to previous observations the bimetallic systems show often positive shifts of one or both metallic peaks due to modifications of electronic structure of the bimetallic system with reference to the pure metal. Son et al. [41] observed $\mathrm{Cu} 2 \mathrm{p}_{3 / 2}$ at 933.6 eV on a metallic thin film of $\mathrm{Al}_{2} \mathrm{Cu}$, thus presenting a shift of $1 \mathrm{eV}$ compared to pure $\mathrm{Cu}$. This effect was also observed in other published works. Liu et al. [42] showed the higher binding energy peak at $933.8 \mathrm{eV}$ for magnetron-sputtered $\mathrm{Al}-33 \% \mathrm{Cu}$ alloy, which was attributed to the metallic copper present in $\mathrm{CuAl}_{2}$ phase. Similarly, Pashusky et al. [43] also 
reported that the increase of $\mathrm{Cu}$ in $\mathrm{Cu}-\mathrm{Al}(100)$ leads to a progressive shift of $\mathrm{Cu} 2 \mathrm{p}_{3 / 2}$ peak to higher binding energies up to $933.2 \mathrm{eV}$. In order to confirm the effect of Cu alloying to $\mathrm{Al}$ and the resulting binding energy shift, a pure metallic $\Theta-\mathrm{Al}_{2} \mathrm{Cu}$ phase was analysed here. The details will be reported in a separate, forthcoming paper. The results confirm the shift of metallic $\mathrm{Cu} 2 \mathrm{p}_{3 / 2}$ peak to $933.5 \mathrm{eV}$ induced by alloying with Al. Moreover, the calculated modified Auger parameter $(1851.4 \mathrm{eV})$ for a pure $\Theta-\mathrm{Al}_{2} \mathrm{Cu}$ intermetallic sample is slightly higher than for pure metallic copper $(1851.2 \mathrm{eV})[39,40]$. The third $\mathrm{Cu} 2 \mathrm{p}_{3 / 2}$ peak at $934.8 \pm$ $0.1 \mathrm{eV}$ is associated to the $\mathrm{Cu}(\mathrm{II})$ mainly in hydroxide state $[39,40]$. The absence of detectable satellite characteristic of $\mathrm{Cu}(\mathrm{II})$ at higher binging energy can be explained by the small amount of $\mathrm{Cu}(\mathrm{II})$.

In order to get more information about the chemical state of copper the analysis of Cu LMM Auger spectra was performed on polished and pre-treated samples (Fig. 7, E) and F), respectively). For the polished sample (Fig. 7, E)), Cu LMN shows a metallic component at $918.1 \pm 0.1 \mathrm{eV}$ and a second component at $916.2 \pm 0.1 \mathrm{eV}$ corresponding to copper oxide or hydroxide, in agreement with previous results $[31,44]$. This fitting was performed by using the Auger line obtained previously for model reference samples (pure metallic copper and copper oxide).

The $\mathrm{Cu} 2 \mathrm{p}_{3 / 2}$ fitting for the sample immersed in nitric acid shows a high intensity peak at $933.7 \pm 0.1 \mathrm{eV}$ related to $\mathrm{Cu}(0)$ in the intermetallic particles (Fig. 7, D)) and a low intensity peak at $932.7 \pm 0.1 \mathrm{eV}$ associated to pure $\mathrm{Cu}(0)$ due to strong copper enrichment and/or $\mathrm{Cu}(\mathrm{I})$. The $\mathrm{Cu} \operatorname{LMN}($ Fig. 7, F)) shows only a metallic component at $918.0 \pm 0.1 \mathrm{eV}$ allowing us to assign the peak at $932.7 \mathrm{eV}$ to metallic $\mathrm{Cu}$. 

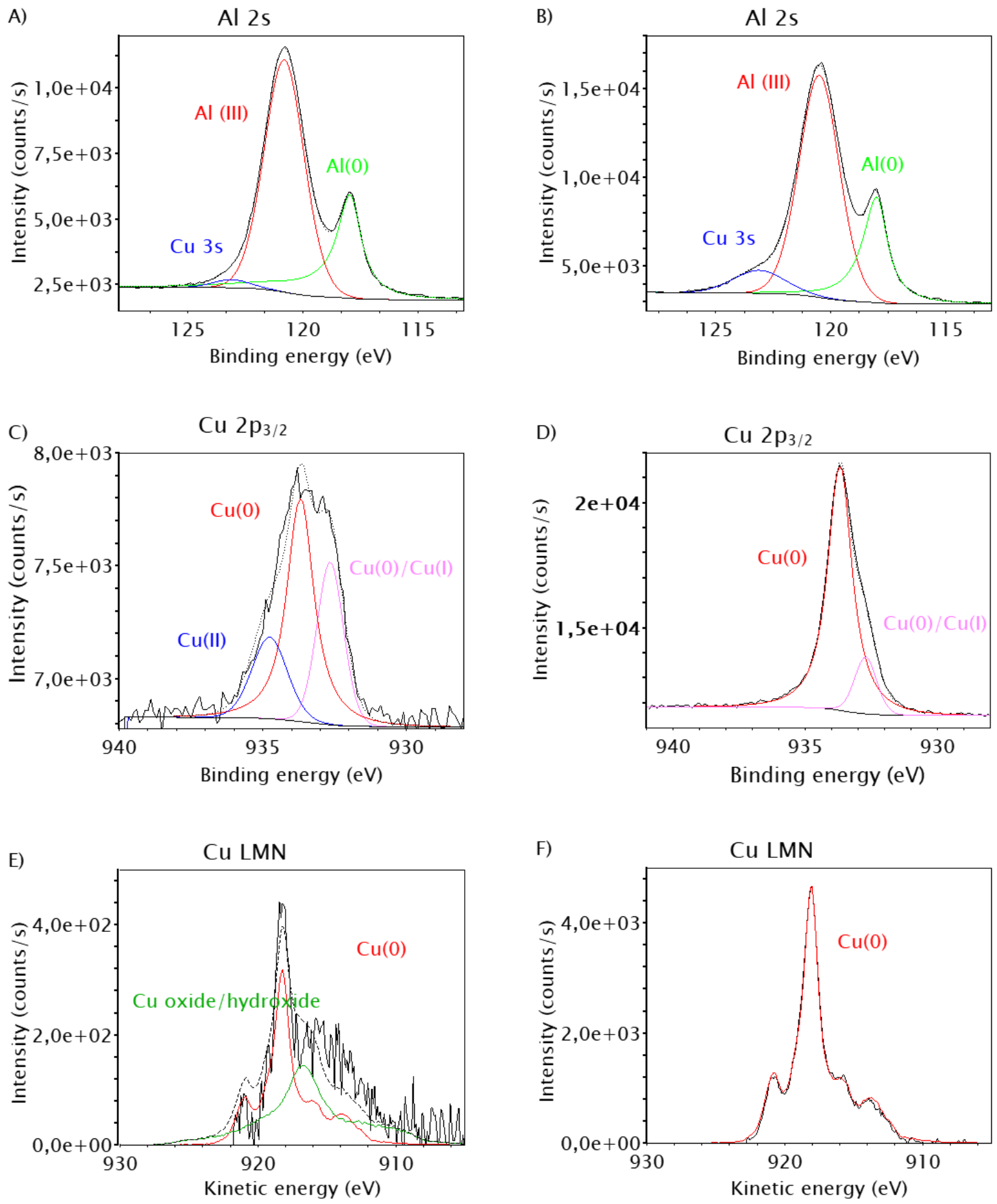

Fig. 7. XPS A) Al $2 s, C) C U 2 p_{3 / 2}$ and E) $C U L M N$ high resolution spectra of AA-2024-T3 mirror polished and XPS B) Al $2 s, D) C U 2 p_{3 / 2}$ and F) CU LMN high resolution spectra of AA-2024-T3 pretreated in $100 \mathrm{~g} / \mathrm{L} \mathrm{HNO}_{3}$ at $50{ }^{\circ} \mathrm{C}$ during $10 \mathrm{~min}$.

Similar peak fittings were performed for XPS data obtained for samples pre-treated in sulphuric acid or in the mixture of acids and the results are presented in supplementary 
information in Erreur ! Source du renvoi introuvable.. The $\mathrm{Cu} 2 \mathrm{p}_{3 / 2}$ peak shape is similar for the samples pre-treated in sulphuric acid and the polished sample, whereas for samples pretreated in the mixture of nitric and sulphuric acids is similar to the samples pre-treated in nitric acid.

The calculated oxide thickness is in the same range for all samples: $2.8 \pm 0.3 \mathrm{~nm}$ after polishing, $3.0 \pm 0.3 \mathrm{~nm}$ after the pre-treatment in $100 \mathrm{~g} / \mathrm{L}$ nitric acid, $3.2 \pm 0.3 \mathrm{~nm}$ after pretreatment in $150 \mathrm{~g} / \mathrm{L}$ sulphuric acid, and $3.0 \pm 0.3 \mathrm{~nm}$ after pre-treatment in the mixture of acids. The oxide thickness was calculated using equation S1 (shown in the supplementary information).

The chemical compositions of samples after polishing and after different treatments are displayed in Table 1. A copper enrichment is observed after all pre-treatments. The sulphuric acid bath led to the highest copper content with almost 5 at.\%. The pre-treatments seem to slightly increase the magnesium content. The analysis of $\mathrm{Mg} 1 \mathrm{~s}$ spectra showed one peak assigned to $\mathrm{Mg}(\mathrm{II})$.

Table 1. Surface composition (in atomic and weight percentage) calculated from XPS data (processed with AvantageTM software).

\begin{tabular}{|c|c|c|c|c|c|c|}
\hline \multicolumn{5}{c|}{ At \% } & \multicolumn{3}{c|}{ Wt \% } \\
\hline & $\% \mathrm{Al}$ & $\% \mathrm{Cu}$ & $\% \mathrm{Mg}$ & $\% \mathrm{Al}$ & $\% \mathrm{Cu}$ & $\% \mathrm{Mg}$ \\
\hline Polished & $99.0 \pm 0.5$ & $0.6 \pm 0.5$ & $0.3 \pm 0.5$ & $98.3 \pm 0.5$ & $1.4 \pm 0.5$ & $0.3 \pm 0.5$ \\
\hline $\mathrm{H}_{2} \mathrm{SO}_{4}$ & $94.3 \pm 0.5$ & $5.1 \pm 0.5$ & $0.6 \pm 0.5$ & $88.3 \pm 0.5$ & $11.2 \pm 0.5$ & $0.5 \pm 0.5$ \\
\hline $\mathrm{HNO}_{3}$ & $96.4 \pm 0.5$ & $2.6 \pm 0.5$ & $1.1 \pm 0.5$ & $93.2 \pm 0.5$ & $5.9 \pm 0.5$ & $0.9 \pm 0.5$ \\
\hline Mixture & $95.8 \pm 0.5$ & $2.3 \pm 0.5$ & $1.2 \pm 0.5$ & $93.6 \pm 0.5$ & $5.4 \pm 0.5$ & $1.0 \pm 0.5$ \\
\hline
\end{tabular}


In order to better understand the evolution of the chemical environment as a function of pre-treatment conditions a copper indicator based on the XPS data was used. The Cu XPS indicator takes into account the attenuation of metallic signal intensities due to the presence of oxide layer on the extreme surface according to equation 1. The Cu XPS indicator is the ratio between the intensity of metallic or oxidised copper peak and the intensity of metallic aluminium according to the following formula [eq 1]:

$$
\text { CuXPS indicator }=\frac{\frac{I_{C u}}{\exp \left(-\frac{d}{\lambda_{C u}^{A l_{2} O_{3}}}\right)}}{\frac{I_{A l(0) 2 s}}{\exp \left(-\frac{d}{\lambda_{A l}^{A l_{2} O_{3}}}\right)}}
$$

The calculations made for the three components of the $\mathrm{Cu} 2 p_{3 / 2}$ peak are shown in Fig. 8 . After all pre-treatments, a significant increase has been noted for the $\mathrm{Cu}(0)$ associated to intermetallic particles. It is well known that selective dissolution of aluminium and $\mathrm{Cu}$ enrichment occurs during pre-treatments leading to dealloying of Cu-rich intermetallic particles $[17,26]$. This can explain the increase of Cu-related signals more significant for the sample pre-treated in sulphuric acid. A small increase of the $\mathrm{Cu}(0) / \mathrm{Cu}(\mathrm{I})$ indicator is observed after pre-treatment in nitric acid and the mixture of acids and much more in sulphuric acid. One possible explanation is the accumulation of metallic copper nanoparticles at the intersection of remnant branches of dealloyed particles and the formation of a copper film as observed by SEM, which covered the dealloyed particle surface $[26,30]$. The other explanation is the copper release, followed by a copper redeposition on the surface during pre-treatment. This phenomenon was already proposed by Buchheit et al. [29], who 
suggested that dealloying of $\mathrm{S}-\mathrm{Al}_{2} \mathrm{Cu}$ could provide mobile copper particles, which can be redistributed across the surface. Viroulaud et al. [35] have also proposed the hypothesis of copper nanoparticles deposition by reduction of $\mathrm{Cu}^{2+}$ present in the solution originating from copper-rich intermetallic particles dissolved during acid pickling step in a bath containing ferric sulphate, nitric acid and sodium bifluoride. The presence of a small amount of $\mathrm{Cu}(\mathrm{I})$ cannot be ruled out even if it is unlikely for $\mathrm{HNO}_{3}$ and acid mixture treated samples because no oxide signal is detected on the Cu Auger peak.

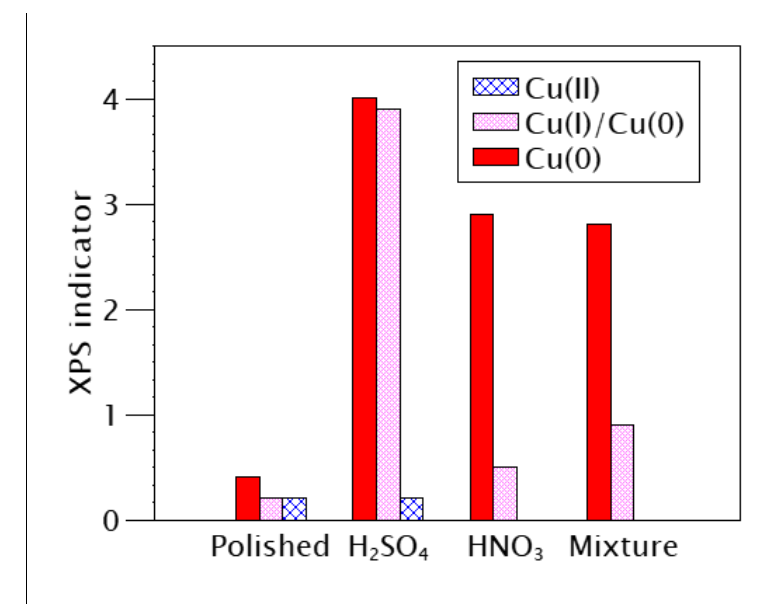

Fig. 8. XPS indicator for the Cu species calculated using [equation 2] before and after pretreatment in nitric and sulphuric acid baths. The metallic copper associated to intermetallic particles is in red, the pure metallic copper or $\mathrm{Cu}(\mathrm{I})$ is in fuchsia and the $\mathrm{Cu}(\mathrm{II})$ in blue.

\subsection{Analysis of pre-treatment baths by ICP-OES}

After the alloy pre-treatments, the used pre-treatment baths were analysed by ICP-OES to measure the weight concentration of aluminium and the two main alloying elements, $\mathrm{Cu}$ and Mg. The concentrations of Al after 10 min immersion in the sulphuric acid, nitric acid and mixture of acids baths were $0.8 \pm 0.3 \mathrm{ppm}, 2.1 \pm 0.3 \mathrm{ppm}$ and $2.8 \pm 0.2 \mathrm{ppm}$, respectively. It can be concluded that the sulphuric acid bath is the least aggressive pre-treatment, leading to the lowest dissolution of Al. 
The Al concentration was used to determine the dissolution rate of the alloy. In a first approach, the hypothesis of a homogeneous (congruent) dissolution of the metallic surface was made. The molar density of Al in metal, $0.1 \mathrm{~mol} / \mathrm{cm}^{3}$, was used for the calculations. Results are presented in Fig. 9. The dissolution rate in the sulphuric acid, nitric acid and mixture of acids baths were $14 \pm 6 \mathrm{~nm} / \mathrm{min}, 37 \pm 6 \mathrm{~nm} / \mathrm{min}$ and $49 \pm 6 \mathrm{~nm} / \mathrm{min}$, respectively. The dissolution rate in the mixture of acids is in the same range $(51 \pm 4 \mathrm{~nm} / \mathrm{min})$ as for the commercial Socosurf bath $\left(\mathrm{HNO}_{3}-\mathrm{H}_{2} \mathrm{SO}_{4}-\mathrm{Fe}\right.$ (III) based deoxidizer), which was studied by Verdalet-Guardiola [25]. Dissolution rates of 2024-T3 can be compared to the ones on pure aluminium (in red) in Figure 10. The dissolution rates of 2024-T3 and pure aluminium are in the same range for each bath. Moreover, the dissolution rate seems to follow the same evolution with bath composition. The dissolution rate is lower in sulphuric acid and higher in nitric acid and mixture of acids. The presence of alloying elements does not seem to affect significantly the dissolution rate of samples in the pre-treatment baths.

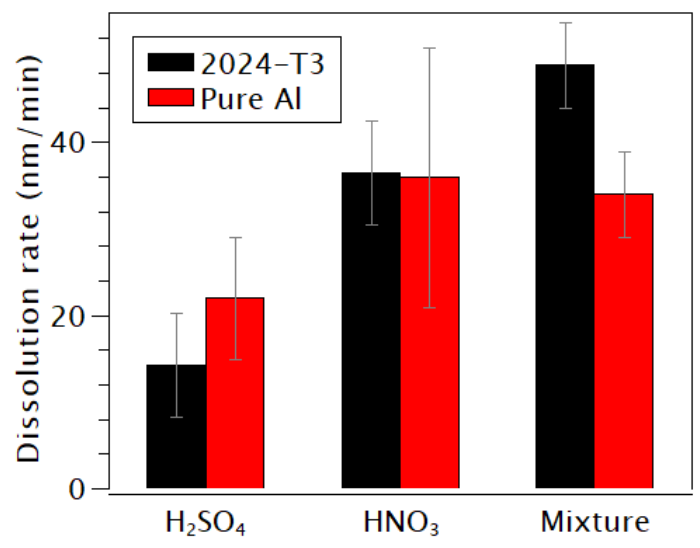

Fig. 9. Dissolution-rate of AA-2024-T3 (black) and pure aluminium (red) in $\mathrm{H}_{2} \mathrm{SO}_{4}, \mathrm{HNO}_{3}$ and mixture of the two acids (measured by ICP-OES).

To compare the effect of pre-treatments on the main alloying elements ( $\mathrm{Cu}$ and $\mathrm{Mg}$ ), the bath composition after pre-teatment was calculated from the element concentrations 
measured by ICP-OES. To compare the results with the composition of the alloy, the contents in $\mathrm{Cu}$ and $\mathrm{Mg}$ were taken as $3.9-5.0 \mathrm{wt} \% \mathrm{Cu}, 1.2-1.8 \mathrm{wt} \% \mathrm{Mg}$ and the rest of aluminium in the bulk alloy. Results are reported in Table 2.

The sulphuric acid bath stands out from the other baths. It has the lowest copper content, $0.6 \pm 0.5 w t \%$, which is lower than the $\mathrm{Cu}$ content in the alloy bulk (3.9 wt\% $\mathrm{Cu}$ ). This very low amount of dissolved Cu could be explained by a preferential dissolution of $\mathrm{Al}$ and $\mathrm{Mg}$ or a redeposition of $\mathrm{Cu}$ on the alloy surface during pre-treatment. The nitric acid and acid mixture baths have similar copper content, with $4.3 \pm 0.5$ wt\% and $4.2 \pm 0.5$ wt\%, respectively. These contents are close to the $\mathrm{Cu}$ content in the alloy but the quantity of dissolved $\mathrm{Cu}$ is considerably increased in the nitric acid and acid mixture with respect to the sulphuric acid bath. This is in agreement with the Cu enrichment on the AA-2024-T3 surface measured by XPS after immersion in the sulphuric acid bath.

For $\mathrm{Mg}$, the sulphuric acid treatment leads to a significant $\mathrm{Mg}$ enrichment in the bath, $7.0 \pm$ 0.9 wt\%, with respect to the $\mathrm{Mg}$ content in the alloy $(1.2-1.8 \mathrm{wt} \% \mathrm{Mg})$. The pre-treatments in the nitric and acid mixture baths give lower $\mathrm{Mg}$ amounts of $3.0 \pm 0.9$ and $2.3 \pm 0.9 \mathrm{wt} \%$, respectively, however these values are also higher than the $\mathrm{Mg}$ content in the bulk alloy. Thus Mg seems preferentially dissolved in the pre-treatment bath, particularly in the sulphuric acid bath. This is in agreement with the lower Mg concentration measured by XPS on the AA-2024-T3 surface after immersion in the sulphuric acid bath. 
Table 2. Amounts of $\mathrm{Al}, \mathrm{Cu}, \mathrm{Mg}$ (in weight percent) dissolved in the pre-treatment baths (measured by ICP-OES) and on the surface (measured by XPS).

\begin{tabular}{|c|c|c|c|c|}
\hline & & $\% \mathrm{Al}$ & $\% \mathrm{Cu}$ & $\% \mathrm{Mg}$ \\
\hline \multicolumn{2}{|l|}{ Alloy composition } & \multirow{8}{*}{ REST } & $3.9-5.0$ & $1.2-1.8$ \\
\hline \multirow{3}{*}{ Dissolved species in the baths measured by ICP-OES } & $\mathrm{H}_{2} \mathrm{SO}_{4}$ & & $0.6 \pm 0.5$ & $7.0 \pm 0.9$ \\
\hline & $\mathrm{HNO}_{3}$ & & $4.3 \pm 0.5$ & $3.0 \pm 0.9$ \\
\hline & Mixture & & $4.2 \pm 0.5$ & $2.3 \pm 0.9$ \\
\hline \multirow{4}{*}{ Surface composition measured by XPS } & Polished & & $1.4 \pm 0.5$ & $0.3 \pm 0.5$ \\
\hline & $\mathrm{H}_{2} \mathrm{SO}_{4}$ & & $11.2 \pm 0.5$ & $0.5 \pm 0.5$ \\
\hline & $\mathrm{HNO}_{3}$ & & $5.9 \pm 0.5$ & $0.9 \pm 0.5$ \\
\hline & Mixture & & $5.4 \pm 0.5$ & $1.0 \pm 0.5$ \\
\hline
\end{tabular}

\section{Discussion}

The pre-treatment in acid solutions leads to surface modifications such as the scalloped surface [18] and the dissolution/removal of intermetallic particles. Deoxidizing in a mixture of $150 \mathrm{~g} / \mathrm{L} \mathrm{H}_{2} \mathrm{SO}_{4}$ and $100 \mathrm{~g} / \mathrm{L} \mathrm{HNO}_{3}$ gives the most attacked surface with a high surface fraction corresponding to defects and holes where all remaining particles are dealloyed. This high density of holes leads to an increase of the surface roughness resulting in less sharp oxide/metal interface. Increased sputtering times in ToF-SIMS in-depth profiles reflect this roughening. The higher dissolution rate of $49 \pm 6 \mathrm{~nm} / \mathrm{min}$ in the acid mixture was also revealed by ICP-OES analysis. The sulphuric acid bath was less aggressive, giving a dissolution rate about $14 \pm 6 \mathrm{~nm} / \mathrm{min}$. However, dissolution/removal of intermetallic particles was also observed.

Regarding the influence of acid treatment on alloying elements, it should be noted that the sulphuric acid solution led to the highest concentration of dissolved magnesium as shown by 
ICP-OES, whereas few differences were observed on pre-treated samples by XPS and ToFSIMS. It is interesting to note that the $\mathrm{Mg}$ amount in the bath was superior to the initial content of $\mathrm{Mg}$ in the alloy. This may be explained by a different dissolution rate of the sides of the samples, with different surface finishing, one side was mirror polished and the other one grinded with SiC paper 1200.

Significant differences related to pre-treatments with different acids were observed for copper._As expected and reported in previous studies [4,12,20-23], surface copper enrichment was clearly evidenced here by XPS and ToF-SIMS. The highest copper content was observed for the sample pre-treated in the sulphuric acid bath.

A metallic copper enrichment at the interface between oxide and metallic substrate after pre-treatments was clearly observed by ToF-SIMS, in agreement with previous studies $[22,23]$. XPS analyses demonstrated an enrichment in $\mathrm{Cu}(0)$ associated to intermetallic particles, which can be explained by the preferential dissolution in favour of copper (dealloying of intermetallic particles) and/or the revealing of new intermetallic particles due to the dissolution of the matrix.

The distribution of copper in the oxide layer is different after the immersion in sulphuric acid with respect to the mixture of acids and the nitric acid. For the sample immersed in sulphuric acid, ToF-SIMS measurements showed that copper is homogenously distributed within the entire oxide layer compared to the polished sample. XPS also confirmed the presence of copper oxide. On the samples pre-treated in $\mathrm{HNO}_{3}$ and $\mathrm{HNO}_{3} / \mathrm{H}_{2} \mathrm{SO}_{4}$, no copper was detected in the oxide layer by ToF-SIMS. Moreover, the Auger signature from Cu LMN XPS spectra confirmed that copper was in the metallic state. 
The copper enrichment could be explained in different ways. Firstly, the metallic copper enrichment on intermetallic particles can be discussed. The common effect of studied pretreatments is the metallic copper enrichment at the metal/oxide interface. In the AA-2024T3, $\mathrm{Cu}$ is present in the intermetallic particles. EDX analyses (Fig. 3) revealed the copper enrichment on dealloyed areas of intermetallic particles. The $\mathrm{Cu}$ enrichment can be explained by the preferential dissolution in favour of copper (dealloying of intermetallic particles). Tardelli et al. [45] already observed this dealloying phenomena and a copper enrichment on $\mathrm{Al}_{2} \mathrm{Cu}, \mathrm{Al}_{2} \mathrm{CuMg}$ and $\mathrm{Al}-\mathrm{Cu}-\mathrm{Fe}-\mathrm{Mn}-\mathrm{Si}$ phase samples after 50 hours of immersion in $200 \mathrm{~g} / \mathrm{L} \mathrm{H}_{2} \mathrm{SO}_{4}$. For the $\mathrm{Al}_{2} \mathrm{Cu}$ sample [45], it was attributed to the formation of a compact copper film at the surface. For the $\mathrm{Al}_{2} \mathrm{CuMg}$ and $\mathrm{Al}-\mathrm{Cu}-\mathrm{Fe}-\mathrm{Mn}-\mathrm{Si}$ samples [45], the formation of copper nodules (around $50 \mathrm{~nm}$ ) at the surface was shown. Even for a low content of copper in the Al-Cu-Fe-Mn-Si, the dissolution of $\mathrm{Al}, \mathrm{Si}, \mathrm{Fe}$ and $\mathrm{Mn}$ led to copper enrichment and the formation of a porous film [45].

Another hypothesis concerning the presence of pure copper can be proposed. The higher intensity of $\mathrm{Cu}(0)$ and/or $\mathrm{Cu}(\mathrm{I})$ XPS signal (Fig. 8) after pre-treatment suggests the presence of pure metallic copper. This could be explained by accumulation of copper at the intersection of remnant branches of dealloyed areas [26] and the formation of a copper film covering the dealloyed particles [45].

A redeposition/redistribution of copper over the surface due to the reduction of mobile $\mathrm{Cu}^{2+}$ for the sample immersed in $\mathrm{H}_{2} \mathrm{SO}_{4}[29,35]$ can also be envisaged. ToF-SIMS in-depth profiles revealed the copper enrichment in the entire oxide layer compared to the polished sample. XPS analysis on this sample (Fig. 8) showed an increase of $\mathrm{Cu}(\mathrm{II})$ and a considerable increase of pure $\mathrm{Cu}(0)$ and/or $\mathrm{Cu}(\mathrm{I})$. ICP-OES analysis revealed a very low dissolution of $\mathrm{Cu}$ during pre- 
treatment, giving less $\mathrm{Cu}$ than in the bulk alloy. This is in accordance with ToF-SIMS and XPS results, which showed the highest copper enrichment after pre-treatment in sulphuric acid (Table 2). These results lead to the conclusion that copper is redeposited during pretreatment in sulphuric acid. The redeposited copper is subsequently oxidized explaining the presence of copper oxide in the oxide layer.

The Cu redeposition has been previously reported by Buchheit et al. [29] and Viroulaud et al. [35]. Campestrini et al. [46] showed the influence of this $\mathrm{Cu}$ on the subsequent steps of alloy treatment. They reported the presence of copper or copper oxide nodule deposits after deoxidizing in sulphuric/phosphoric bath inhibiting the growth of the chromate film above the matrix.

\section{Conclusions}

The AA-2024-T3 alloy has been characterized by SEM, XPS and ToF-SIMS after deoxidizing in sulphuric acid, nitric acid, and a mixture of both acids. Baths were also characterised by ICPOES. The most important conclusions of the influence of the acid treatment on the surface chemical composition are the following:

- No significant evolution of the oxide thickness was observed after pre-treatment

- The common effect of the studied deoxidizers is copper enrichment at the metal/oxide interface. The highest copper enrichment was observed for $\mathrm{H}_{2} \mathrm{SO}_{4}$ bath. Metallic copper was observed at the metal/oxide interface and copper oxide in the entire oxide layer.

- The $\mathrm{HNO}_{3}$ and $\mathrm{HNO}_{3} / \mathrm{H}_{2} \mathrm{SO}_{4}$ baths led to the metallic copper enrichment and different surface morphologies. With $\mathrm{HNO}_{3} / \mathrm{H}_{2} \mathrm{SO}_{4}$, all intermetallic particles were 
dealloyed and many of them were removed whereas for $\mathrm{HNO}_{3}$ bath, only the $\mathrm{Al}_{2} \mathrm{Cu}$ and $\mathrm{Al}_{2} \mathrm{CuMg}$ particles were attacked and bigger particles remained intact.

- Copper enrichment was principally attributed to dealloying of intermetallic particles, resulting in formation of Cu-rich remnant, according to the EDX and XPS measurements. In the case of $\mathrm{H}_{2} \mathrm{SO}_{4}$ deoxidizer, it could also be attributed to the copper redeposition as concluded from ICP-OES analyses.

\section{Acknowledgments}

The authors would like to acknowledge the IRT-M2P for funding this research in the frame of Project EVEREST. Region Ile-de-France is also acknowledged for partial support for the XPS and ToF-SIMS equipment. Mrs. Françoise Pillier (LISE, UMR 8235) is acknowledged for the assistance for the EDX measurements. 
References:

[1] K.A. Yasakau, M.L. Zheludkevich, M.G.S. Ferreira, Role of intermetallics in corrosion of aluminum alloys. Smart corrosion protection, in: Intermet. Matrix Compos., Elsevier, 2018: pp. 425-462. https://doi.org/10.1016/B978-0-85709-346-2.00015-7.

[2] R.G. Buchheit, A Compilation of Corrosion Potentials Reported for Intermetallic Phases in Aluminum Alloys, J. Electrochem. Soc. 142 (1995) 3994. https://doi.org/10.1149/1.2048447.

[3] S.A. Kulinich, A.S. Akhtar, On conversion coating treatments to replace chromating for Al alloys: Recent developments and possible future directions, Russ. J. Non-Ferr. Met. 53 (2012) 176-203. https://doi.org/10.3103/S1067821212020071.

[4] R. Viroulaud, J. Światowska, A. Seyeux, S. Zanna, J. Tardelli, P. Marcus, Influence of surface pretreatments on the quality of trivalent chromium process coatings on aluminum alloy, Appl. Surf. Sci. 423 (2017) 927-938. https://doi.org/10.1016/j.apsusc.2017.06.246.

[5] J. Qi, T. Hashimoto, J. Walton, X. Zhou, P. Skeldon, G.E. Thompson, Formation of a trivalent chromium conversion coating on AA2024-T351 alloy, J. Electrochem. Soc. 163 (2016) C25-C35.

[6] T.G. Harvey, Cerium-based conversion coatings on aluminium alloys: a process review, $\begin{array}{llllll}\text { Corros. } & \text { Eng. } & \text { Sci. } & \text { Technol. } & 48 & \text { (2013) }\end{array}$ https://doi.org/10.1179/1743278213Y.0000000089.

[7] P. Campestrini, H. Terryn, A. Hovestad, J.H.W. de Wit, Formation of a cerium-based conversion coating on AA2024: relationship with the microstructure, Surf. Coat. Technol. 176 (2004) 365-381. https://doi.org/10.1016/S0257-8972(03)00743-6.

[8] A.E. Hughes, J.D. Gorman, T.G. Harvey, A. Galassi, G. McAdam, Development of permanganate-based coatings on aluminum alloy 2024-T3, Corrosion. 62 (2006) 773780.

[9] S.A. Kulinich, A.S. Akhtar, P.C. Wong, K.C. Wong, K.A.R. Mitchell, Growth of permanganate conversion coating on 2024-Al alloy, Thin Solid Films. 515 (2007) 83868392. https://doi.org/10.1016/j.tsf.2007.04.164.

[10] A.S. Hamdy, I. Doench, H. Möhwald, Intelligent self-healing corrosion resistant vanadia coating for AA2024, Thin Solid Films. 520 (2011) 1668-1678. https://doi.org/10.1016/j.tsf.2011.05.080.

[11] H. Guan, R.G. Buchheit, Corrosion Protection of Aluminum Alloy 2024-T3 by Vanadate Conversion Coatings, CORROSION. $60 \quad$ (2004) 284-296. https://doi.org/10.5006/1.3287733.

[12] J. Qi, A. Němcová, J.R. Walton, X. Zhou, P. Skeldon, G.E. Thompson, Influence of preand post-treatments on formation of a trivalent chromium conversion coating on AA2024 alloy, Thin Solid Films. $616 \quad$ (2016) 270-278. https://doi.org/10.1016/j.tsf.2016.08.044.

[13] L. Li, A.L. Desouza, G.M. Swain, Effect of Deoxidation Pretreatment on the Corrosion Inhibition Provided by a Trivalent Chromium Process (TCP) Conversion Coating on AA2024-T3, J. Electrochem. Soc. 161 (2014) C246-C253. https://doi.org/10.1149/2.031405jes. 
[14] Y. Guo, G.S. Frankel, Characterization of trivalent chromium process coating on AA2024-T3, Surf. Coat. Technol. $206 \quad$ (2012) 3895-3902. https://doi.org/10.1016/j.surfcoat.2012.03.046.

[15] X. Verdalet-Guardiola, J.-P. Bonino, S. Duluard, B. Fori, C. Blanc, Influence of the alloy microstructure and surface state on the protective properties of trivalent chromium coatings grown on a 2024 aluminium alloy, Surf. Coat. Technol. 344 (2018) 276-287. https://doi.org/10.1016/j.surfcoat.2018.03.046.

[16] J. Qi, Y. Miao, Z. Wang, Y. Li, X. Zhang, P. Skeldon, G.E. Thompson, Influence of Copper on Trivalent Chromium Conversion Coating Formation on Aluminum, J. Electrochem. Soc. 164 (2017) C611-C617. https://doi.org/10.1149/2.0261712jes.

[17] J. Alba-Galvín, L. González-Rovira, M. Bethencourt, F. Botana, J. Sánchez-Amaya, Influence of Aerospace Standard Surface Pretreatment on the Intermetallic Phases and $\mathrm{CeCC}$ of 2024-T3 Al-Cu Alloy, Metals. $9 \quad$ (2019) 320. https://doi.org/10.3390/met9030320.

[18] T.G. Harvey, A.E. Hughes, S.G. Hardin, T. Nikpour, S.K. Toh, A. Boag, D. McCulloch, M. Horne, Non-chromate deoxidation of AA2024-T3: Sodium bromate-nitric acid (20$\left.60^{\circ} \mathrm{C}\right)$ Appl. Surf. Sci. $254 \quad$ (2008) 3562-3575. https://doi.org/10.1016/j.apsusc.2007.11.061.

[19] A. Boag, A.E. Hughes, A.M. Glenn, T.H. Muster, D. McCulloch, Corrosion of AA2024-T3 Part I: Localised corrosion of isolated IM particles, Corros. Sci. 53 (2011) 17-26. https://doi.org/10.1016/j.corsci.2010.09.009.

[20] U. Tiringer, J. Kovač, I. Milošev, Effects of mechanical and chemical pre-treatments on the morphology and composition of surfaces of aluminium alloys 7075-T6 and 2024-T3, Corros. Sci. 119 (2017) 46-59. https://doi.org/10.1016/j.corsci.2017.02.018.

[21] C.E. Moffitt, D.M. Wieliczka, H.K. Yasuda, An XPS study of the elemental enrichment on aluminum alloy surfaces from chemical cleaning, Surf. Coat. Technol. 137 (2001) 188196. https://doi.org/10.1016/S0257-8972(00)01121-X.

[22] K.J. Vander, A.W. Hassel, M. Stratmann, Effect of Pretreatment on the Intermetallics in Aluminum Alloy 2024-T3, Z. Für Phys. Chem. 219 (2005) 1505-1518. https://doi.org/10.1524/zpch.2005.219.11.1505.

[23] Y. Liu, M.A. Arenas, A. de Frutos, J. de Damborenea, A. Conde, P. Skeldon, G.E. Thompson, P. Bailey, T.C.Q. Noakes, Influence of nitric acid pre-treatment on Al-Cu alloys, Electrochimica $\quad$ Acta. $53 \quad$ (2008) 4454-4460. https://doi.org/10.1016/j.electacta.2008.01.026.

[24] A.E. Hughes, A.M. Glenn, N. Wilson, A. Moffatt, A.J. Morton, R.G. Buchheit, A consistent description of intermetallic particle composition: An analysis of ten batches of AA2024T3: Microprobe analyses of ten batches of AA2024-T3, Surf. Interface Anal. 45 (2013) 1558-1563. https://doi.org/10.1002/sia.5207.

[25] V. Verdalet-Guardiola, Réactivité dans les bains de prétraitement et mécanismes de croissance des couches de conversion au chrome trivalent sur un alliage d'aluminium 2024, phdthesis, Université Toulouse 3, 2019.

[26] T. Hashimoto, X. Zhang, X. Zhou, P. Skeldon, S.J. Haigh, G.E. Thompson, Investigation of dealloying of $S$ phase (Al2CuMg) in AA 2024-T3 aluminium alloy using high resolution 2D and 3D electron imaging, Corros. Sci. 103 (2016) 157-164. https://doi.org/10.1016/j.corsci.2015.11.013. 
[27] O. Gharbi, N. Birbilis, K. Ogle, In-Situ Monitoring of Alloy Dissolution and Residual Film Formation during the Pretreatment of Al-Alloy AA2024-T3, J. Electrochem. Soc. 163 (2016) C240-C251. https://doi.org/10.1149/2.1121605jes.

[28] G.M. Scamans, N. Birbilis, R.G. Buchheit, Corrosion of Aluminum and its Alloys, in: Shreirs Corros., Elsevier, 2010: pp. 1974-2010. https://doi.org/10.1016/B978044452787-5.00095-0.

[29] R.G. Buchheit, R.P. Grant, P.F. Hlava, B. Mckenzie, G.L. Zender, Local Dissolution Phenomena Associated with S Phase (Al2CuMg) Particles in Aluminum Alloy 2024-T3, J. Electrochem. Soc. 144 (1997) 2621. https://doi.org/10.1149/1.1837874.

[30] Z. Qi, C. Zhao, X. Wang, J. Lin, W. Shao, Z. Zhang, X. Bian, Formation and Characterization of Monolithic Nanoporous Copper by Chemical Dealloying of $\mathrm{Al}-\mathrm{Cu}$ Alloys, J. Phys. Chem. C. 113 (2009) 6694-6698. https://doi.org/10.1021/jp810742z.

[31] P. Cornette, S. Zanna, A. Seyeux, D. Costa, P. Marcus, The native oxide film on a model aluminium-copper alloy studied by XPS and ToF-SIMS, Corros. Sci. 174 (2020) 108837. https://doi.org/10.1016/j.corsci.2020.108837.

[32] M. Li, A. Seyeux, F. Wiame, P. Marcus, J. Światowska, Insights on the Al-Cu-Fe-Mn intermetallic particles induced pitting corrosion of Al-Cu-Li alloy, Corros. Sci. 176 (2020) 109040. https://doi.org/10.1016/j.corsci.2020.109040.

[33] A.-I. Stoica, J. Światowska, A. Romaine, F. Di Franco, J. Qi, D. Mercier, A. Seyeux, S. Zanna, P. Marcus, Influence of post-treatment time of trivalent chromium protection coating on aluminium alloy 2024-T3 on improved corrosion resistance, Surf. Coat. Technol. 369 (2019) 186-197. https://doi.org/10.1016/j.surfcoat.2019.04.051.

[34] A. Seyeux, G.S. Frankel, N. Missert, K.A. Unocic, L.H. Klein, A. Galtayries, P. Marcus, ToFSIMS Imaging Study of the Early Stages of Corrosion in Al-Cu Thin Films, J. Electrochem. Soc. 158 (2011) C165. https://doi.org/10.1149/1.3568944.

[35] R. Viroulaud, Protection contre la corrosion des alliages d'aluminium par la conversion TCP : influence de la chimie de surface, phdthesis, Université Pierre et Marie Curie Paris VI, 2016. https://tel.archives-ouvertes.fr/tel-01647213/document (accessed May 22, 2018).

[36] X. Zhou, G.E. Thompson, P. Skeldon, K. Shimizu, H. Habazaki, G.C. Wood, The valence state of copper in anodic films formed on Al-1at.\% Cu alloy, Corros. Sci. 47 (2005) 1299-1306. https://doi.org/10.1016/j.corsci.2004.07.026.

[37] Y. Liu, M.A. Arenas, P. Skeldon, G.E. Thompson, H. Habazaki, K. Shimizu, P. Bailey, T.C.Q. Noakes, Generation of copper nanoparticles during alkaline etching of an Al-30at.\%Cu alloy, Corros. Sci. 48 (2006) 1874-1884. https://doi.org/10.1016/j.corsci.2005.07.011.

[38] P. Marcus, C. Hinnen, I. Olefjord, Determination of attenuation lengths of photoelectrons in aluminium and aluminium oxide by angle-dependent $x$-ray photoelectron spectroscopy, Surf. Interface Anal. 20 (1993) 923-929. https://doi.org/10.1002/sia.740201108.

[39] G. Deroubaix, P. Marcus, X-ray photoelectron spectroscopy analysis of copper and zinc oxides and sulphides, Surf. Interface Anal. 18 (1992) 39-46. https://doi.org/10.1002/sia.740180107.

[40] M.C. Biesinger, Advanced analysis of copper X-ray photoelectron spectra: Advanced analysis of copper X-ray photoelectron spectra, Surf. Interface Anal. 49 (2017) 13251334. https://doi.org/10.1002/sia.6239. 
[41] K.-A. Son, N. Missert, J.C. Barbour, J.J. Hren, R.G. Copeland, K.G. Minor, Growth and Oxidation of Thin Film Al2Cu, J. Electrochem. Soc. 148 (2001) B260. https://doi.org/10.1149/1.1376635.

[42] Y. Liu, P. Bailey, T.C.Q. Noakes, G.E. Thompson, P. Skeldon, M.R. Alexander, Chemical environment of copper at the surface of a CUAI2 model alloy: XPS, MEIS and TEM analyses, Surf. Interface Anal. 36 (2004) 339-346. https://doi.org/10.1002/sia.1743.

[43] A. Pashusky, XPS and AES studies of Cu-Al(100) alloy surfaces, Vacuum. 44 (1993) 997999. https://doi.org/10.1016/0042-207X(93)90286-J.

[44] P. Cornette, Approche expérimentale et théorique de l'inhibition de corrosion de surfaces métalliques, phdthesis, Université Pierre et Marie Curie - Paris VI, 2018. https://hal.archives-ouvertes.fr/tel-01903566.

[45] J. Tardelli, Etude du comportement électrochimique des phases intermétalliques des alliages d'aluminium 2214-T6 et 7050-T74: approche multi-échelle de matériaux polyphasés, phdthesis, Université de Lorraine, 2012. http://www.theses.fr/2012LORR0082 (accessed May 22, 2018).

[46] P. Campestrini, Microstructure-related quality of conversion coatings on aluminium alloys, phdthesis, Delft University of Technology, 2002. 